\title{
Oral Cancer Frequency at Different Sub Sites Presenting At a Tertiary Care Hospital in Karachi Pakistan
}

\author{
Imtiaz Ather Siddiqui*,Hurtamina Khan, Riaz Siddiqui, Mahum Hafeez, Muhammad Razzak Dogar, Wajeeha \\ Shahid and Sameer Qureshi
}

ENT Department, Jinnah Sindh Medical University, Pakisthan

Submission: March 27, 2017; Published: April 06, 2017

*Corresponding author: Imtiaz Ather Siddiqui, Senior Registrar ENT department Jinnah Sindh Medical University Karachi, Pakisthan, Tel +92 300 2005500; Email: siddykee@yahoo.com

\section{Abstract}

Introduction: Carcinoma of oral cavity is amongst the first ten commonest malignancies in Pakistan. Oral cavity sub sites includes lips, gum, floor of mouth, mucosa of cheeks, vestibule, anterior two third of tongue, retro molar trigone, hard and soft palate and uvula these sub sites show a variation of trend, onset of cancer. Causes are Aerica nut, tobacco and low consumption of alcohol in our society as compared to developed part of the globe.

Objective: To determine the frequency of oral cancer in sub sites of oral cavity.

Study design: Cross sectional study

Setting: Venue: Ear nose throat, Head and Neck surgery Department, Jinnah Postgraduate Medical Centre Jinnah Sind Medical University Karachi.

Duration: Four years, from 1st January 2013 to 1st January 2016.

Subject and Methods: A total of 105 patients having chronic oral ulcer of three months or more duration, growth in oral cavity, either gender reporting for treatment at ENT JPMC OPD were registered for the study. Detail like sub site oral lesion, technique of sampling like punch biopsy to be done by expression biopsy and Histopathologically reports were entered.

Results: The average age of the patients was $48.52 \pm 5.24$ years. There were $61 \%$ male and $39 \%$ were female. The commonest sites involved were cheek mucosa, lips, tongue, gum with (36.2\%), (25.7\%), (20\%), (18\%) respectively.

Conclusion: Cheek mucosa is the commonest site of oral cancer with middle age group and male predominance. These results are similar to previous studies with acceptable differences in proportions and common sites involved. However, most of the studies have shown male predominance and middle to old age involvement.

Keywords: Carcinoma; Oral cavity; Cheek mucosa; Oral Cancer; Oral Subsites; Intra Oral

\section{Introduction}

Oral cancer is one of the top ten malignancies across the globe. It is second to none lung cancer in male and breast cancer in females. In Indian sub continent it is one of the major problems [1]. Approximately $90 \%$ of oral cancers are squamous cell carcinoma (SCC), which is seen in older men, typically on the lip or lateral part of the tongue. Oral squamous cell carcinoma (OSCC) is the most common intra oral site manifesting as a chronic, indurated ulcer. Oral SCC is particularly common in the developing world. There is concern about an increase in younger patients. The etiology appears to be multifactorial and strongly related to lifestyle, mostly habits and diet (particularly tobacco alone or in betel, and alcohol use), Unfortunately, the parts of the world where oral cancer is most common are also those where descriptive information (i.e., incidence, mortality, prevalence) is least available. In certain countries, such as Sri Lanka, India, Pakistan, and Bangladesh, oral cancer is the most common cancer. In parts of India, oral cancer can represent more than $50 \%$ of all cancers [2]. Oral cavity anatomically when 
mapped out, extends from the skin vermillion junction lips to the junction of soft and hard plate above and to circum vallate papillae below [3].

Oral cavity sub sites includes lips, gum, floor of mouth, mucosa of cheeks, vestibule, anterior two third of tongue, retro molar trigone, hard and soft palate and uvula [4] these sub sites show a variation of trend, onset of cancer nut, tobacco and low consumption of alcohol in our society as compared to developed part of the globe. The incidence of lip cancer has decreased and is equals to the females. While an increased incidence of tongue cancer is coming up which was not in this part of the world before. A more dramatic increase in cheek cancer is being reported in both genders [5]. so trends in sub sites of oral cancer are changing. These changing trends affect the mortality rates of oral cancer so the intent of the study is to see the current trend of cancer site of oral cavity.

\section{Objective}

To determine the frequency of oral cancer in sub sites of oral cavity.

Operational definition: Lesion in the oral cavity includes the following features:

a. Mucosa of cheek \& floor of mouth.

b. Lips (Upper and lower lip)

c. Tongue (Up to foramen caecum)

d. Gums (From the teeth to Buccal mucosa)

\section{Material and Methods}

Study design: Cross sectional study

Setting: Venue: Ear, Nose, Throat, Head and Neck Surgery Department, Jinnah Postgraduate Medical Centre (ENT JPMC) \& Jinnah Sindh Medical University Karachi.

Duration: Four years, from $1^{\text {st }}$ January 2013 to $1^{\text {st }}$ January 2016.

Sample Size: 105 patients on the bases of $p=19 \%, d=8 \%$ with 95\% Confidence interval.

Sampling Technique: Non-probability purposive

Sampling Selection:

\section{Inclusion criteria:}

a. Patients with the history of ulcers in oral cavity at least since three months.

b. Biopsy proven cases of oral cancer

c. $\quad 18$ and above up to 60 years.

d. Either Gender

\section{Exclusion criteria:}

a. Recurrent or residual disease after surgical treatment or chemo radiotherapy

b. Patients not willing for Histo pathological analysis of oral ulcers with a history of three months/ clinically evident oral cancer.

\section{Data Collection Procedure}

Patients having chronic oral ulcer of three months or more duration, growth in oral cavity, either gender reporting for treatment at ENT OPD at Jinnah Sindh Medical University, were registered for the study after informed consent. Patients with residual oral cancer post surgical / oncological treatment were not registered. Patients not willing for Histopathological analysis of their oral ulcer or growth were also not part of the study. Demographic data was entered in the Performa designed for the study. Detail like sub site oral lesion, technique of sampling like punch biopsy weredone by expression biopsy and Histopathological report was entered. A sample of such Performa is also attached.

\section{Data analysis procedure}

Data was entered and analyzed in Statistical software (SPSS10). Frequency and percentage were computed for gender, sub site of oral malignancy. Mean and standard deviation of age was calculated. Stratification was done to control effect modified like gender, age to observe the effect on outcomes.

\section{Results}

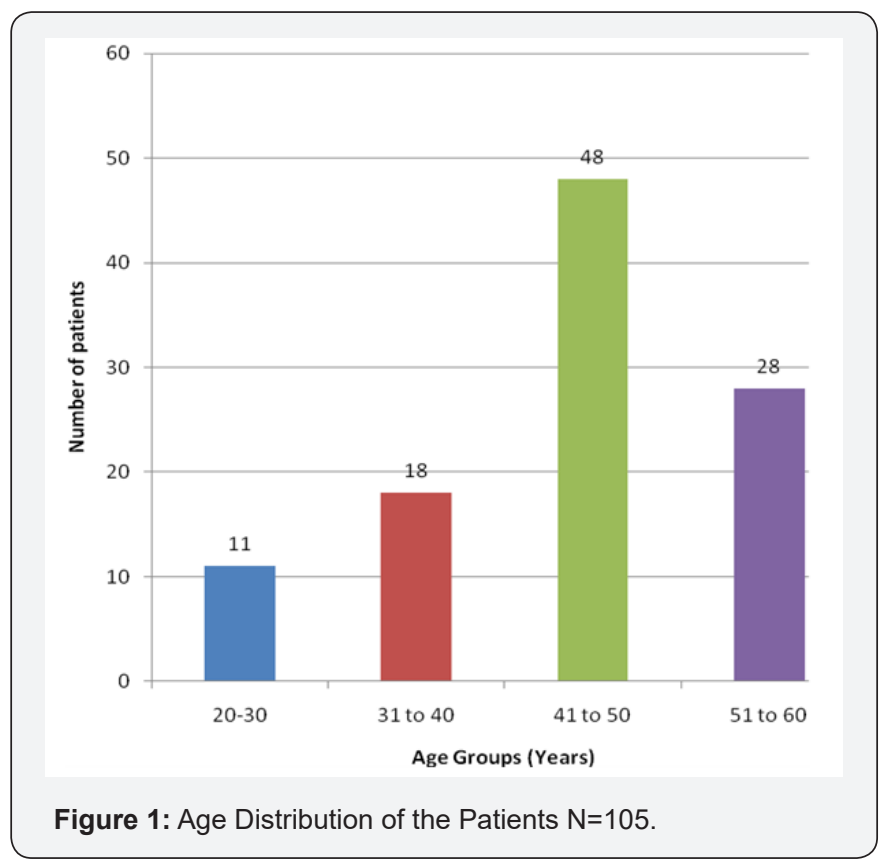

A total of 105 patients with the history of ulcer in oral cavity at least three months and biopsy proven cases of oral cancer were included in this study. Most of the patients were 45 to 50 years of age as presented in Figure 1. The average age of the patients was $48.52 \pm 5.24$ years (95\%CI: 46.65 to 49.32 ). There were $61 \%$ male and $39 \%$ were female as shown in Figure 2. 


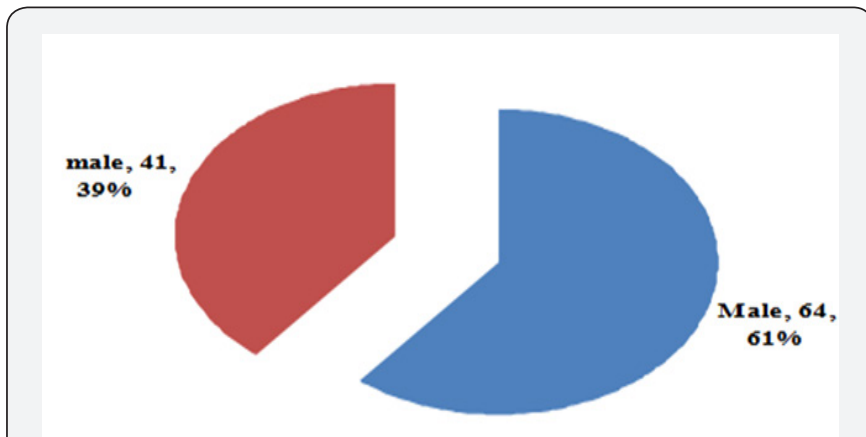

Figure 2: Gender Distribution of the Study Patients N=105.

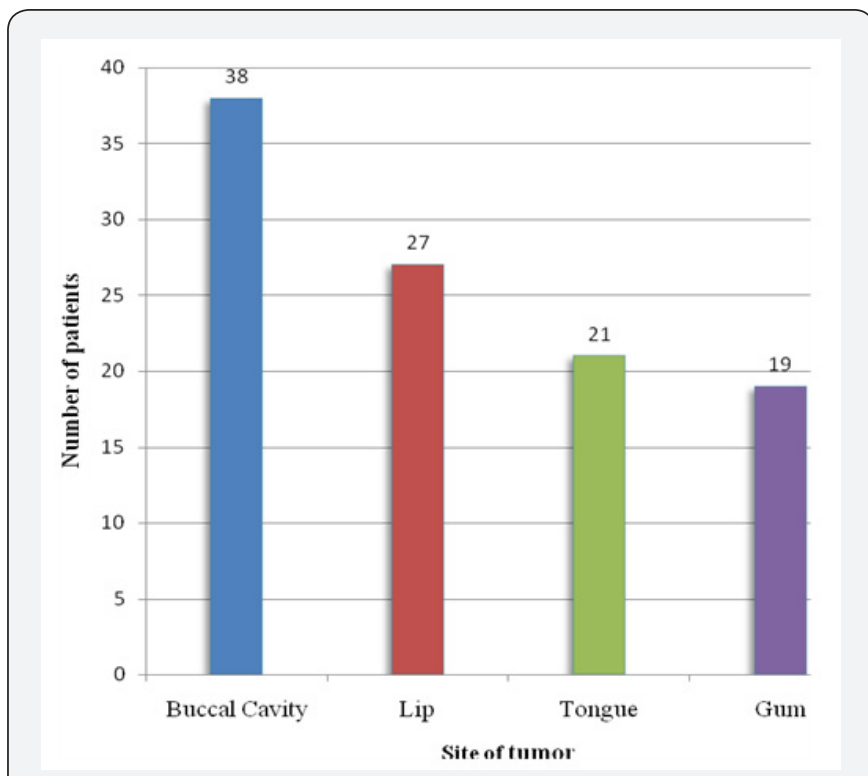

Figure 3: Frequency of Oral Cancer in Sub Site of Oral Cavity.

Frequency of oral cancer in sub sites of oral cavity is presented in Figure 3. The commonest sites involved were cheek mucosa, lips, tongue, gum with (36.2\%), (25.7\%), (20\%), (18\%) respectively. It was interesting to note that among the all age groups all the sub sites of oral cavity were most prevalent in middle age (41-50) years rather than young age or old age group. Similarly frequency of oral cancer in sub sites of oral cavity with respect to gender is also presented in Tables 1-3.

Table 1: Descriptive Statistics of Age $n=105$.

\begin{tabular}{|c|c|}
\hline Statistics & Age (Years) \\
\hline Mean \pm SD & $48.52 \pm 5.24$ \\
\hline 95\% Confidence Interval & 46.65 to 49.32 \\
\hline Median (IQR) & $49(8)$ \\
\hline Maximum & 20 \\
\hline Minimum & 60 \\
\hline
\end{tabular}

Table 2: Frequency of Oral Cancer in Sub site of Oral Cavity with respect to Age Groups.

\begin{tabular}{|c|c|c|c|c|c|}
\hline \multirow{2}{*}{$\begin{array}{c}\text { Site of Squamous } \\
\text { Cell Carcinoma }\end{array}$} & $\mathbf{n}$ & $\mathbf{5}$ Age Groups (Years) \\
\cline { 3 - 6 } & $\mathbf{2 0 - 3 0}$ & $\mathbf{3 1 - 4 0}$ & $\mathbf{4 1 - 5 0}$ & $\mathbf{5 1 - 6 0}$ \\
\hline Buccal Cavity & 38 & 3 & 6 & 20 & 9 \\
\hline Lip & 27 & 2 & 5 & 10 & 10 \\
\hline Tongue & 21 & 2 & 4 & 9 & 6 \\
\hline Gum & 19 & 4 & 3 & 9 & 3 \\
\hline
\end{tabular}

Table 3: Frequency of Oral Cancer in Sub site of Oral Cavity with respect to Gender.

\begin{tabular}{|c|c|c|c|}
\hline \multirow{2}{*}{$\begin{array}{c}\text { Site of Squamous Cell } \\
\text { Carcinoma }\end{array}$} & $\mathbf{n}$ & \multicolumn{2}{|c|}{ Gender } \\
\cline { 3 - 4 } & & Male & Female \\
\hline Buccal Cavity & 38 & 23 & 15 \\
\hline Lip & 27 & 15 & 12 \\
\hline Tongue & 21 & 12 & 9 \\
\hline Gum & 19 & 14 & 5 \\
\hline
\end{tabular}

\section{Discussion}

Oral cancer is the third most common cancer after stomach and cervical cancer in the developing nations. Oral cancers include cancers of lips, tongue, gums, floor of mouth, cheek mucosa, palate and other parts of mouth as per international classification of diseases [6]. The prevalence of lip cancer appears to be decreasing, but the prevalence of intra-oral cancer appears to be rising in many countries, especially in younger people [7]. Incisional biopsy, when appropriately stained, is essential to confirm the diagnosis. A biopsy must be performed on any oral mucosal lesion suggestive of carcinoma, including any ulcer that does not heal within 2 - 3 weeks. Studies on oral cancers are required more in such parts of the world, where these cancers are most common.

Our study of 105 patients with 39\% female and 61\% male and mean of $48.52 \pm 5.24$ years. The results found that commonest sites involved were Buccal cavity, lips, tongue, gum with $(36.2 \%),(25.7 \%),(20 \%),(18 \%)$ respectively. It was interesting to note that among the all age groups all the sub sites of oral cavity were most prevalent in middle age (41-50) years rather than young age or old age group. Another recent study of 398 cases conducted in southern Punjab Pakistan, has slightly different results. This shows commonest site in oral cavity was Alveolus $37.9 \%$, Tongue $31.2 \%$, Oral mucosa $13.4 \%$, soft palate, lips and floor of the mouth $2 \%$ to be the least [8]. These results are different from our results. The reason may be that risk factors like Pan Quid Beetle nut, Manipuri, Gutka, Gem, Tobacco chewing, Naswar consumption is more common 
in a mega city Karachi which has a population of twenty million. This needs further research on these diverse findings. Another recent study in Karachi by Akram S, results are similar to our study. This shows that maximum no.0f patients were from age group 41-50 years [9]. Involvement of comparatively younger age group in oral cancer especially cheek mucosa may be due to earlier exposure of population towards risk factors.

Cancer of the oral cavity is one of the common malignancies in developing countries. It is common in males compared to females and is usually seen after middle age. The incidence of oral cancer is increasing, however, in the younger generation in recent years. This has also been found in our study. The study by Bhat and colleagues explore the distribution of oral cavity and oropharyngeal malignancies in relation to age, sex, site, personal habits, histological type and differentiation. Out of the 100 patients studied, the majority were males. The average age was 60 years. Similarly our study with similar sample size and male predominance; however, shows majority of middle age participants with mean age around 48 years. Tobacco consumption in the form of smoking and smokeless tobacco was the common etiological factor noticed. Anatomically, more anterior parts in the oral cavity are the common sites involved. Squamous cell carcinoma was the most common histological type, with the majority of them being well differentiated [10].

Further the study also showed the Buccal mucosa was the most common site involved (22\%), similarly our study also showed commonest site was Buccal cavity (36.2\%). However, there were variations in proportions of other sites, as the above study found the other commonest sites as followed by oral tongue (21\%) and base of tongue (10\%), tonsil (9\%), lip (7\%) in comparison to our study lips, tongue, gum with $(25.7 \%),(20 \%)$, (18\%) respectively. The above study also finds other sites such as alveolus and hard palate (6\%), Vallecula, soft palate (5\%), pharyngeal wall (3\%), retro molar trigone (1\%), which we didn't find in our study.

The study by Marocchio and colleagues evaluate records of patients diagnosed as having OSCC between the years 1960 and 2008 was retrieved. A total of 1,564 cases were reviewed. Overall, males were more affected than females (3:1). Our study also showed male predominance in the sample of oral cavity cancer patients but with a small sample [3]. The higher incidence of oral and oropharyngeal malignancies in males may be due to the high rate of tobacco and alcohol consumption among males. Moreover, tobacco is consumed in both smoking and chewing form in males, whereas in our society, females do not usually indulge in smoking. The difference can also be attributed to more males seeking early medical consultation [11]. In contrast to above study that showed the significant increase in the rate of OSCC in patients over 80 years we observed the most prevalent age group was middle age between 41-50 years rather than old age. Also the above study found gingiva was the most affected site, but the frequency of lower lip involvement increased in the last time period. We also found lips and gingiva involvement but the commonest prevalent site involved in our study was Buccal cavity.

Study by Wahid and colleagues in Abbottabad situated in northern region of Pakistan, explored 50 carcinoma cases, including $30(60 \%)$ males and $20(40 \%)$ females. Among these, $47(94 \%)$ were diagnosed as squamous cell carcinomas, that consisted $30(63.82 \%)$ males and $17(36.17 \%)$ females. The other $6 \%$ lesions were histologically diagnosed as malignant melanoma, adenocarcinoma and acinar cell carcinoma. The age of squamous cell carcinoma cases was $41-71$ years. The maximum number of squamous cell carcinomas (34\%) effected Buccal mucosa. The other common sites were lip (26\%), tongue (21\%) and gums (19\%)4. Our study with comparatively large sample of 105 patients and mean age of around 48 years with majority of patients with middle age group, similarly found Buccal cavity followed by lips, tongue, gum with (36.2\%), (25.7\%), (20\%), (18\%) respectively. This close resemblance can be justified by similar geographic, cultural The results of the study are comparable with other such studies done in Pakistan and elsewhere in the world showing commonality of factors associated with the development of the disease in this region of the country, which necessitates a detailed prospective study [4]. However while analyzing for squamous cell carcinoma only results in terms of proportion are different, as reported by Ayaz and colleagues in Karachi, Pakistan.

A total of 268 oral mucosal biopsy reports were studied which constituted $6.6 \%$ of all malignant tumors reported during this period. Amongst the SCC group, 116 (43.28\%) cases were well differentiated, $128(47.76 \%)$ cases were moderately differentiated and 16 (5.97\%) cases were poorly differentiated. Tongue was the commonest site involved in 116 (44\%) cases followed by Buccal mucosa 88 (33.3\%) cases as opposite to our study Buccal mucosa being the commonest followed by tongue. Conclusion: Squamous cell carcinoma is the predominant type of oral cancer and tongue is the commonest site of origin for these cancers. In our patients, oral cancer presented at a relatively early age group [12]. Early detection of Oral Cancer by a simple method of Toluidine blue in any clinical set up [13]. Avoidance of known risk factors like Tobacco, Pan Quad, Gutka, and Alcohol can reduce the incidence and burden of Oral Cancer.

\section{Conclusion}

Our study results showed Buccal cavity is the commonest site of oral cancer with middle age group and male predominance. These results are similar to previous studies with acceptable differences in proportions and common sites involved. However, most of the studies have shown male predominance and middle to old age involvement. Based on our findings and inferences and strength and limitations, we recommend further future epidemiological studies with large sample, multiple settings and objectives to reach a firm conclusion. 


\section{Authors Contribution}

IAS Conceived, designed, analyzed data, and did manuscript writing.

HK Data collection, reviewed, editing and final approval of manuscript, and Literature search.

MH Did data collection, reviewed and Literature search. Proof reading of manuscript.

MR Did data collection and proof reading of manuscript. Final approval of manuscript.

WS Review and final approval of manuscript.

SQ Final review of manuscript.

\section{References}

1. Bhurgri Y, Rahim A, Bhutto K, Bhurgri A, Panjanl PK, et al. (1998) Incidence of carcinoma of the oral cavity in Karachi district south. J Pak Med Assoc 48(11): 321-325.

2. Scully C (2011) Cancers of the oral mucosa. Drugs \& Diseases.

3. Jang WI, WU HG, Park CI, Kim KH, Sung MW, et al. (2008) Treatment of patients with clinically Lymph node negative squamous cell carcinoma of oral cancer. Jpn J Clin Oncol 38(6): 395-401.

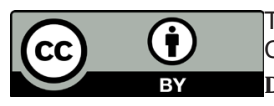

his work is licensed under Creative Commons Attribution 4.0 License

DOI: $10.19080 /$ GJO.2017.06.555687
4. Wahid A, Ahmed S, Sajjad M (2005) Pattern of oral carcinoma of oral cavity reporting in dental department of Ayub Medical College. J Ayub Med Coll Abbottabad 17(1): 65-66.

5. Bhurgri Y (2005) Cancer of the oral cavity -trends in Karachi south (1995-2002). Asian Pac J Cancer Prev 6(1): 22-26.

6. Who (2010) World Health Organization. International Classification of diseases (ICD).

7. Jemal A, Murray T, Samuels A, Ghafoor A, Ward E, et al. (2003) American Cancer Society. Cancer Statistics, 2003. CA Cancer J Clin 53(1): 5-26.

8. Baig Safdar, Bhutto Riaz, Muhammad Sher (2015) Epidemiology of Oral Cancer in southern Punjab Pakistan. Pjmhs 4: 1269-1271.

9. Akram S, Mirza T, Mirza MA, Qureshi M (2013) Emerging patterns in Clinico-pathological spectrum of Oral Cancers. Pak J Med Sci 29(3): 783-787.

10. Bhat SP, Naik R, Swetadri GK, D'souza H, Jayaprakash CS, et al. Clinicopathological Spectrum of Malignancies of Oral Cavity and Oropharynx- Our Experience in a Referral Hospital.

11. Marocchio LS, Lima J, Sperandio FF, Correa L, de Sousa SO (2010) Oral squamous cell carcinoma: an analysis of 1,564 cases showing advances in early detection. J Oral Sci 52(2): 267-273.

12. Ayaz B, Saleem K, Azim W, Shaikh A (2013) A Clinico-Pathological Study of Oral Cancers. Pak J Med Sci 27: 29-32.

13. Siddiqui IA, Umar M, Siddiqui RA, Tariq SM (2006) Role of Toluidine blue in early detection of Oral cancer. Pak J Med Sci 22: 2184-2187.

\section{Your next submission with Juniper Publishers} will reach you the below assets

- Quality Editorial service

- Swift Peer Review

- Reprints availability

- E-prints Service

- Manuscript Podcast for convenient understanding

- Global attainment for your research

- Manuscript accessibility in different formats

( Pdf, E-pub, Full Text, Audio)

- Unceasing customer service

Track the below URL for one-step submission https://juniperpublishers.com/online-submission.php 